\title{
Época de aplicação de nitrogênio e de início da irrigação na fitotoxicidade causada pela aplicação de imidazolinonas em arroz tolerante
}

\author{
Nitrogen application and flood timing on injury caused by imidazolinone herbicide on tolerant rice
}

\author{
Luis Antonio de Avila ${ }^{{ }^{*}}$ Diogo Machado Cezimbra' ${ }^{\mathrm{II}}$ Enio Marchesan ${ }^{\mathrm{I}}$ \\ Sérgio Luiz de Oliveira Machado ${ }^{\text {III }}$ Martin Pasini" ${ }^{\text {II }}$ Cláudio Glier ${ }^{\text {II }}$ Rafael Bruck Ferreira ${ }^{\text {II }}$
}

RESUMO

O uso de herbicidas do grupo químico das imidazolinonas, em cultivares de arroz tolerantes, pode causar fitotoxicidade inicial nessas cultivares. Práticas integradas de manejo, como época de aplicação de nitrogênio $e$ início da irrigação, podem reduzir a fitotoxicidade, acelerando a recuperação das plantas. Em vista disto, o presente trabalho teve por objetivo avaliar o efeito de épocas de aplicação de nitrogênio em cobertura e início da irrigação, visando a minimizar a fitotoxicidade, no arroz IRGA 422 CL, causada pelo herbicida composto pela mistura formulada de imazethapyr + imazapic $\left(75+25 \mathrm{~g} \mathrm{~L}^{-1}\right)$, na dose de $1,25 \mathrm{~L} \mathrm{ha}^{-1}$, acrescido do adjuvante não iônico (Dash $H C^{\circledR}$ ), na concentração de $0,5 \% \mathrm{v} / \mathrm{v}$. O experimento foi conduzido nos anos agrícolas de 2005/06 e 2006/07, em Santa Maria, Rio Grande do Sul (RS), no delineamento experimental de blocos ao acaso, em esquema bifatorial $(4 \times 3)+1$, com quatro repetições. $O$ fator A refere-se a épocas de início da irrigação por inundação (um, cinco, 10 e 15 dias após aplicação do herbicida - DAT) e o fator $B$, às épocas de aplicação de nitrogênio em cobertura (1, 5 e 10DAT), mais uma testemunha não tratada com o herbicida. Na cultivar tolerante, a fitotoxicidade observada em plantas de arroz, após a aplicação do herbicida, é menor se a adubação nitrogenada em cobertura for realizada precocemente (até o quinto dia após a aplicação do herbicida) e a irrigação da lavoura for realizada no dia seguinte ao da aplicação do herbicida ou tardiamente (15DAT); não afetando a produtividade de grãos. A inundação tardia não é recomendável, pois pode favorecer a emergência de arroz vermelho em áreas infestadas.

Palavras-chave: arroz Clearfield ${ }^{\circledR}$, irrigação, manejo, nitrogênio em cobertura.

\section{ABSTRACT}

The use of imidazolinones herbicides in tolerant rice genotypes can cause injury to rice plant. Integrated management practices, such as, water and nitrogen management could be able to reduce this problem, either reducing the injury or speeding the recovery. For this reason, it was carried out a field experiment with the objective of evaluating the effects of flood and nitrogen topdressing application timing on the rice plant injury caused by the formulated mixture of the herbicides imazethapyr and imazapic (75 and $25 \mathrm{~g}$ a.i. $\mathrm{L}^{-1}$ ) at $1.25 \mathrm{~L} \mathrm{ha}^{-1}$, in the IRGA $422 \mathrm{CL}$ rice cultivar. The experiment was carried out on 2005/06 and 2006/ 07 growing season, in a lowland area in the city of Santa Maria, RS, Brazil. The experimental design was a randomized block in a factorial scheme $(4 \times 3)+1$ with split plot and four replications. The factor $A$ were the flood timing (1, 5, 10 and 15 days after herbicide application - DAT) and the factor $B$ were the topdressing nitrogen application (1, 5 and 10DAT), plus an untreated check. The results showed that in the tolerant rice cultivar, the injury promoted by the use of the herbicide was lower when the nitrogen application was done earlier (until the $5^{\text {th }}$ day after herbicide application) and the flooding was done on the day following the herbicide application or at 15 days after herbicide application, without impact on grain yield. But, regarding to the late flooding (15DAT), this is not a recommendable practice because it can favor the red rice emergence in infested areas.

Key words: Clearfield rice ${ }^{\mathrm{TM}}$, flooding management, nitrogen topdressing.

IDepartamento de Fitotecnia, Universidade Federal de Santa Maria (UFSM), 97105-900, Santa Maria, RS, Brasil. E-mail: laavilabr@gmail.com.*Autor para correspondência.

${ }^{\text {IIC }}$ urso de Agronomia, UFSM, Santa Maria, RS, Brasil.

IIIDepartamento de Defesa Fitossanitária, UFSM, Santa Maria, RS, Brasil. 


\section{INTRODUÇÃO}

O sistema Clearfield ${ }^{\circledR}$ é uma ferramenta eficiente para o controle do arroz vermelho (STEELE et al., 2002), que é a principal planta daninha na lavoura de arroz irrigado (ELEFTHEROHORINOS \& DHIMA, 2002). Nesse sistema, são utilizados herbicidas do grupo das imidazolinonas em cultivares tolerantes. No Brasil, o herbicida utilizado é composto pela mistura formulada de imazethapyr e imazapic. Esses herbicidas têm como mecanismo de ação a inibição da acetolactato sintase (ALS) ou acetoidróxido sintase (AHAS), primeira enzima da rota de síntese dos aminoácidos de cadeia ramificada, isoleucina, leucina e valina (FONTANA et al., 2007).

As cultivares utilizadas nesse sistema foram obtidas por meio de mutação induzida pelo agente químico EMS (Etilmetasulfonato) e, em alguns genótipos, por segunda mutação induzida por raio gama (CROUGHAN et al., 1994). Assim, os genótipos disponíveis no mercado podem ser divididos em duas classes, o primeiro com tolerância e o segundo com tolerância avançada, com respostas diferenciadas à aplicação dos herbicidas (AVILA et al., 2005a). Os genótipos tolerantes podem sofrer dano de fitotoxicidade com as doses recomendadas do herbicida. Porém, o genótipo com tolerância avançada suporta doses acima da dose recomendada sem demonstrar sintomas de fitotoxicidade. Nas situações em que ocorre elevada fitotoxicidade em cultivares tolerantes (STEELE et al., 2002; PELLERIN \& WEBSTER, 2004; VILLA et al., 2006b), pode resultar na redução da produtividade (STEELE et al., 2002; PELLERIN \& WEBSTER, 2004).

A fitotoxicidade inicial dos herbicidas do grupo das imidazolinonas sobre cultivares de arroz tolerante tem sido demonstrada por vários autores (OTTIS et al., 2003; YOKOYAMA et al., 2003; VILLA et al., 2006a). Alguns fatores de manejo podem afetar a intensidade de fitotoxicidade, dentre eles, a época de início da irrigação por inundação, e a irrigação mais precoce possibilita menor injúria dos herbicidas e/ou recuperação mais rápida das plantas (DORNELLES et al., 2005; FLECK et al., 2003). Outra prática de manejo que pode influenciar a fitotoxicidade é a adubação nitrogenada. O nitrogênio é um nutriente essencial para o crescimento das plantas, podendo acelerar a recuperação de plantas sob efeito tóxico do herbicida. Pesquisas realizadas comprovaram a importância da adubação nitrogenada como fator de incremento de colmos e panículas por área e produtividade do arroz (GHOBRIAL, 1983; SINGH \& PILLAI, 1996; MARIOT et al., 2003). Além disso, o nitrogênio desempenha papel importante na formação dos órgãos reprodutivos e dos grãos do arroz (BARBOSA FILHO, 1987).

Em vista do exposto, torna-se importante avaliar a integração de práticas de manejo na redução da fitotoxicidade das imidazolinonas, em plantas de arroz, no sistema Clearfield ${ }^{\circledR}$. Este trabalho teve como objetivo avaliar o efeito da época de aplicação de nitrogênio e da época do início da irrigação por inundação na redução da fitotoxicidade observada no arroz tolerante, após a aplicação do herbicida composto pela mistura formulada de imazethapyr e imazapic (75 + $\left.25 \mathrm{~g} \mathrm{~L}^{-1}\right)$.

\section{MATERIAL E MÉTODOS}

O experimento foi conduzido nas safras 2005/ 06 e 2006/07, em uma área de várzea sistematizada do Departamento de Fitotecnia da Universidade Federal de Santa Maria (UFSM), localizada em Santa Maria, Rio Grande do Sul (RS). O solo é classificado como Planossolo Hidromórfico eutrófico arênico e pertence à unidade de mapeamento Vacacaí (EMBRAPA, 1999). O delineamento experimental utilizado foi de blocos casualizados, com quatro repetições, em esquema bifatorial (4x3)+1, acrescido de uma testemunha não tratada com o herbicida. $O$ fator A refere-se a épocas de início da irrigação por inundação (um, cinco, 10 e 15 dias após aplicação do herbicida - DAT) e o fator B, as épocas de aplicação de nitrogênio em cobertura (1,5 e 10DAT), mais uma testemunha não tratada com o herbicida.

A semeadura foi realizada no sistema convencional, no ano agrícola 2005/06 e no sistema de plantio direto no ano agrícola 2006/07, sendo realizada, respectivamente, em 13/10/2005 e 14/10/2006. A adubação de base foi realizada com a aplicação de $350 \mathrm{~kg} \mathrm{ha}^{-1}$ do adubo de fórmula NPK 5-20-20 (N-P $\mathrm{O}_{5}$ $\mathrm{K}_{2} \mathrm{O}$ ). A cultivar 'IRGA 422CL' foi semeada na densidade de $110 \mathrm{~kg}$ de sementes $\mathrm{ha}^{-1}$, com o auxílio de uma semeadora-adubadora contendo 11 linhas espaçadas de $0,17 \mathrm{~m}$. Após semeadura do arroz, foram construídas taipas de isolamento entre as parcelas.

Nos dois anos agrícolas, o herbicida composto pela mistura formulada de imazethapyr e imazapic (75 e $25 \mathrm{~g}$ i.a. $\mathrm{L}^{-1}$ ) foi aplicado na dose de 1,25L ha-1 ${ }^{-1}$ em pós-emergência no estádio $\mathrm{V}_{4}$ (COUNCE et al., 2000). Essa dose corresponde à dosagem recomendada acrescida de $25 \%$, com os objetivos de promover a maior fitotoxicidade e expressar os efeitos dos tratamentos. Para a aspersão dos herbicidas, foi usado um pulverizador costal de precisão, pressurizado com $\mathrm{CO}_{2}$, provido de uma barra contendo quatro pontas do tipo leque da série Teejet XR110.015, 
espaçadas 0,50m, e calibrado para uma vazão de $125 \mathrm{~L}$ ha ${ }^{-1}$ de calda herbicida. A adubação nitrogenada de cobertura foi realizada na forma de uréia parcelada em duas épocas: a primeira $\left(60 \mathrm{~kg} \mathrm{ha}^{-1} \mathrm{de} \mathrm{N}\right)$ foi realizada conforme os tratamentos descritos anteriormente (um, cinco, 10 dias após a aplicação do herbicida) e a segunda (60kg ha-1 de N) foi realizada na iniciação do primórdio floral do arroz ( $\mathrm{R}_{0}$ ) (COUNCE et al., 2000).

As variáveis avaliadas foram a avaliação visual de fitotoxicidade, realizada aos 16 e 23 (2005/ 2006) e aos 13, 20, 32 e 40 (2006/07) dias após a aplicação dos herbicidas (DAT), sendo utilizados os valores percentuais (BURRILL et al., 1976); o número de panículas $\mathrm{m}^{-2}$ determinadas na colheita e a produtividade de grãos. Os dados foram submetidos aos testes de normalidade e homogeneidade da variância. As variáveis que não atenderam à pressuposição de normalidade, antes da análise da variância, foram transformadas para arco seno $\sqrt{\% / 100}$. Após esses procedimentos, os dados foram submetidos à ANOVA, e as médias foram comparadas entre si pelo teste de Tukey e pelo teste de Dunnett $(\mathrm{P} \leq 0,05)$, para contraste com a testemunha. Não houve interação entre os fatores para nenhuma das variáveis estudadas, por isso foram avaliados apenas os efeitos dos fatores principais.

\section{RESULTADOS E DISCUSSÃO}

No ano agrícola 2005/06, a fitotoxicidade observada nas plantas de arroz, na avaliação realizada aos 16DAT, foi menor no tratamento com início da irrigação no dia posterior à aplicação do herbicida (1DAT), não diferindo da inundação aos 15DAT. Já na avaliação realizada aos 23DAT não foi verificada diferença significativa entre os tratamentos, demonstrando recuperação das plantas de arroz, com fitotoxicidade média de 4,5\% (Tabela 1). No ano agrícola 2006/07, a fitotoxicidade observada na primeira avaliação (13DAT) também foi menor nos tratamentos com inundação precoce, não diferindo da inundação aos 15DAT. A partir da avaliação realizada aos 20DAT, houve menor fitotoxicidade, não havendo diferenças entre os tratamentos com relação à irrigação e demonstrando a rápida recuperação das plantas. Esses resultados são similares àqueles verificados por DAL MAGRO (2006), que observou recuperação de plantas de arroz que foram submetidas à deriva de imazethapyr e imazapic com inundação precoce. Os resultados corroboram também os resultados de PANOZZO (2008), o qual verificou menor fitotoxicidade em plantas pelo herbicida penoxsulan, nos tratamentos em que a entrada de água foi realizada um dia após a aplicação do herbicida.

A menor fitotoxicidade, nos tratamentos com a irrigação precoce, pode ser atribuída à diluição do herbicida na solução do solo (AVILA et al., 2005c) e também à alta mobilidade do herbicida (FIRMINO et al., 2008), podendo ser transportado para profundidades maiores no perfil do solo e posicionando-se muitas vezes abaixo da zona radicular do arroz. Nesse sentido, KRAEMER (2008) determinou que imazethapyr lixivia

Tabela 1 - Fitotoxicidade observada em plantas da cultivar de arroz 'IRGA 422 CL’ após aplicação de 1,25L ha ${ }^{-1}$ do herbicida composto pela mistura formulada de imazethapyr e imazapic (75 e $25 \mathrm{~g}$ i.a. $\mathrm{L}^{-1}$ ), em resposta a épocas de aplicação de nitrogênio e inundação da lavoura. Santa Maria, RS, 2008'.

\begin{tabular}{|c|c|c|c|c|c|c|}
\hline Época de inundação & $16 \mathrm{DAT}^{2 /}$ & 23DAT & 13DAT & 20DAT & 32DAT & 40DAT \\
\hline $1 \mathrm{DAT}$ & $39,5 c^{3 /}$ & $2,1^{\text {ns }}$ & $1,2 b^{*}$ & $5,0^{\mathrm{ns}}$ & $0,8^{\mathrm{ns}}$ & $2,0^{\mathrm{ns}}$ \\
\hline $5 \mathrm{DAT}$ & $48,1 \mathrm{ab}$ & 5,4 & $13,0 \mathrm{a}$ & 3,8 & 3,4 & 1,5 \\
\hline $10 \mathrm{DAT}$ & 51,7 a & 7,1 & $15,6 \mathrm{a}$ & 3,3 & 2,7 & 2,3 \\
\hline $15 \mathrm{DAT}$ & 42,5 bc & 3,3 & $7,4 \mathrm{ab}$ & 5,2 & 1,3 & 1,3 \\
\hline \multicolumn{7}{|c|}{ Época de aplicação de N } \\
\hline $1 \mathrm{DAT}$ & $45,8^{\text {ns }}$ & $4,4^{\mathrm{ns}}$ & $10,3^{\text {ns }}$ & $3,6^{\mathrm{ns}}$ & $0,3 \mathrm{~b}$ & $0 \mathrm{~b}$ \\
\hline 5 DAT & 43,1 & 5,3 & 7,8 & 5,3 & $2,3 \mathrm{ab}$ & $1,6 \mathrm{ab}$ \\
\hline $10 \mathrm{DAT}$ & 47,5 & 3,8 & 10,4 & 4,1 & $3,4 \mathrm{a}$ & 3,7 a \\
\hline Média & 45,5 & 4,5 & 9,5 & 4,3 & 2,0 & 1,8 \\
\hline CV (\%) & 6,2 & 17,2 & 13,7 & 13,8 & 15,7 & 16,0 \\
\hline
\end{tabular}

\footnotetext{
1/ Antes da análise da variância, para fins de normalização da sua distribuição dos dados, os valores foram transformados para arco seno $\sqrt{\% / 100}$.

${ }^{2 /}$ Dias após a aplicação do herbicida (DAT).

${ }^{n s}$ Não significativo pelo teste $\mathrm{F}(\mathrm{P}=0,05)$.
} 
até $20 \mathrm{~cm}$ em solo de várzea, independentemente do sistema de cultivo. WIELEWICHI et al. (1998) afirmam que a antecipação do início da irrigação proporciona maior absorção de nutrientes e maior produção de massa seca na parte aérea, na planta de arroz, o que possibilitaria a recuperação mais rápida das plantas. Já a menor fitotoxicidade observada com irrigação tardia se deve provavelmente à degradação de parte do herbicida, que é realizada por microorganismos aeróbicos (SENSEMAN, 2007). Porém, o atraso na irrigação poderia ocasionar aumento da emergência de arroz vermelho se sementes destes estivessem presentes na área, reduzindo assim o potencial produtivo do arroz irrigado.

Com relação às épocas de aplicação de nitrogênio, em 2005/06, não houve diferença significativa entre os tratamentos nas primeiras avaliações (16 e 23DAT em 2005/06 e 13 e 24DAT em 2006/07); porém, no ano agrícola de 2006/07, as diferenças entre os tratamentos foram percebidas mais tardiamente. Dessa forma, no ano agrícola de 2006/07, nas avaliações de fitotoxicidade realizadas aos 32 e 40DAT, a aplicação precoce de nitrogênio (1 e 5DAT) proporcionou menor fitotoxicidade em plantas devido ao herbicida, demonstrando assim uma recuperação mais rápida que os demais tratamentos. Em trabalho realizado por LARROSA (2008), a aplicação de N, em diferentes estádios, promoveu efeito significativo no teor de clorofila, e as maiores concentrações foram obtidas nos tratamentos em que a aplicação foi realizada no estádio $\mathrm{V}_{4}$, o que pode ter influenciado a rapidez com que as plantas se recuperaram do estresse causado pelo herbicida. Há evidências de que o herbicida imazethapyr inibe a atividade da enzima nitrato redutase, reduzindo a absorção de nitrato pelas raízes (ZABALZA et al., 2006). A inibição da absorção de nitrogênio é acompanhada pela redução do conteúdo de nitrogênio e concomitantemente pela inibição da translocação para a parte aérea da planta. Há também evidências que imazethapyr inibe a assimilação da amônia (SCARPONI et al., 1995). Assim, o suprimento precoce de nitrogênio, até o quinto dia após a aplicação do herbicida, pode compensar esses efeitos adversos no metabolismo do nitrogênio.

A precocidade da aplicação de nitrogênio, com a posterior inundação, reduz a fitotoxicidade das plantas de arroz pelo herbicida, pois ocorre a incorporação desse nutriente ao solo, aumentando a eficiência de seu uso e evitando as perdas por volatilização. Nesse sentido, LARROSA et al. (2001) reportam incrementos no acúmulo de nitrogênio total e do número de colmos $\mathrm{m}^{-2}$, quando a aplicação de nitrogênio foi seguida da inundação da área.

A produtividade de grãos não foi afetada pelas épocas de aplicação de nitrogênio ou pela época de início da irrigação (Tabela 2). Resultados semelhantes foram obtidos por AVILA et al. (2005b), os quais verificaram que a produtividade do arroz não foi reduzida quando o início da irrigação ocorreu até os 14DAT. Porém, é necessário enfatizar que não ocorreu infestação de arroz-vermelho na área do experimento. Assim, é provável a obtenção de resultados diferentes

Tabela 2 - Produtividade de grãos e número de panículas de arroz $\mathrm{m}^{-2}$ após aplicação de $1,25 \mathrm{~L} \mathrm{ha}^{-1}$ do herbicida composto pela mistura formulada de imazethapyr e imazapic ( 75 e $25 \mathrm{~g}$ i.a. $\mathrm{L}^{-1}$ ), em resposta a épocas de aplicação de nitrogênio e inundação da lavoura. Santa Maria, RS, 2008.

\begin{tabular}{|c|c|c|c|c|c|c|}
\hline \multirow{2}{*}{ Época de inundação } & \multicolumn{3}{|c|}{-------------Produtividade $\left(\mathrm{kg} \mathrm{ha}^{-1}\right)$------------ } & \multicolumn{3}{|c|}{------------Panículas (número m²) ----------- } \\
\hline & $2005 / 06$ & $2006 / 07$ & Média & $2005 / 06$ & $2006 / 07$ & Média \\
\hline $1 \mathrm{DAT}^{1 /}$ & 8602 & 6084 & $2 / * 7343^{\text {ns }}$ & 427 & 423 & $* 425^{\mathrm{ns}}$ \\
\hline 5DAT & 8509 & 6141 & * 7325 & 388 & 437 & * 413 \\
\hline 10DAT & 8642 & 5932 & * 7287 & 435 & 406 & * 421 \\
\hline 15DAT & 8574 & 6469 & * 7521 & 431 & 422 & * 427 \\
\hline \multicolumn{7}{|c|}{ Época de aplicação de N } \\
\hline 1DAT & 8486 & 6322 & $* 7404^{\mathrm{ns}}$ & 447 & 440 & $* 443^{\mathrm{ns}}$ \\
\hline 5DAT & 8720 & 6238 & * 7479 & 394 & 439 & * 416 \\
\hline 10DAT & 8538 & 5910 & * 7224 & 420 & 388 & * 404 \\
\hline Média & 8581 & 6157 & 7369 & 420 & 422 & 421 \\
\hline Testemunha & 6380 & 2886 & 4.633 & 381 & 316 & 349 \\
\hline CV (\%) & & & 10,0 & & & 17,4 \\
\hline
\end{tabular}

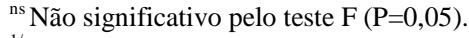

${ }^{1 /}$ Dias após a aplicação do herbicida (DAT).

${ }^{2 /}$ Médias precedidas por asterisco $(*)$ diferem da testemunha sem aplicação de herbicidas pelo teste de Dunnett $\left.\mathrm{P}=0,05\right)$.
} 
em áreas com alta infestação de arroz-vermelho, especialmente quando a irrigação for realizada tardiamente. Quando comparadas com a testemunha, as médias de produtividade para os dois anos agrícolas apresentaram diferença significativa, demonstrando redução do rendimento de grãos devido à competição com as plantas daninhas presentes na área da parcela testemunha. Isso ocorre também para o número de panículas por metro quadrado.

Apesar da fitotoxicidade inicial observadadas nas plantas de arroz, não houve redução na produtividade de grãos, independentemente dos tratamentos testados. É importante destacar que a cultivar 'IRGA 422 CL' é tolerante às imidazolinonas e, quando as práticas de manejo na condução da lavoura são aquelas preconizadas, o arroz recupera-se mais rapidamente da fitotoxicidade inicial. Esse resultado é semelhante ao resultado obtido por OTTIS et al. (2003), os quais também reportam intensa fitotoxicidade decorrente da aplicação de imazethapyr em pós-emergência inicial, contudo sem efeito negativo na produtividade de grãos.

\section{CONCLUSÕES}

A fitotoxicidade observada em plantas de arroz após a aplicação do herbicida composto pela mistura formulada de imazethapyr e imazapic (75 e $25 \mathrm{~g}$ $\mathrm{L}^{-1}$ ), na dose de $1,25 \mathrm{~L} \mathrm{ha}{ }^{-1}$, é menor se a adubação nitrogenada em cobertura for realizada precocemente (até o quinto dia após a aplicação do herbicida) e a irrigação da lavoura for realizada no dia seguinte ao da aplicação do herbicida ou tardiamente (15DAT); não afetando a produtividade de grãos. Porém, a inundação tardia não é recomendável, pois pode favorecer a emergência de arroz vermelho em áreas infestadas.

\section{AGRADECIMENTOS}

À Fundação de Amparo à Pesquisa do Estado do Rio Grande do Sul (FAPERGS) e ao Conselho Nacional de Desenvolvimento Científico e Tecnológico (CNPq), pela concessão de recursos financeiros por meio dos editais PROADE 3 (processo n. 0523126) e Universal (processo $n$. 474677/2006-0), respectivamente. À Universidade Federal de Santa Maria, pela bolsa iniciação científica (FIPE/UFSM).

\section{REFERÊNCIAS}

AVILA, L. A. de, et al. Assessment of acetolactate synthase (ALS) tolerance to imazethapyr in red rice ecotypes (Oryza spp.) and imidazolinone tolerant/resistant rice varieties (Oryza sativa). Pest Management Science, Inglaterra, v.61, n.2, p.171-178, 2005a. Disponível em: <http://dx.doi.org/10.1002/ ps.966>. Acesso em: 16 abr. 2009. Doi: 10.1002/ps.966.

AVILA, L.A. de, et al. Effect of flood timing on red rice (Oryza spp.) control with imazethapyr applied at different dry-seeded rice growth stages. Weed Technology, v.19, n.2, p.476-480, 2005b. Disponível em: <http://www.bioone.org/doi/abs/ 10.1614/WT-04-181>. Acesso em: 16 abr. 2009. Doi: 10.1614/ WT-04-181.

AVILA, L.A. de, et al. Efeito da umidade do solo na sorção e disponibilidade de imazetapir em três solos. In: CONGRESSO BRASILEIRO DE ARROZ IRRIGADO, 5., 2005, Santa Maria. Anais... Santa Maria: SOSBAI, 2005c. p. 511-513.

BARBOSA FILHO, M.P. Nutrição e adubação do arroz: sequeiro e irrigado. Piracicaba: Potafós, 1987. 129p. (Boletim Técnico, 9).

BURRILL, L.C. et al. Field manual for weed control research. Corvallis: International Plant Protection Center, Oregon State University, 1976. 59p.

COUNCE, P.A. et al. A uniform, objective and adaptive system for expressing rice development. Crop Science, v.40, n.2, p.436-443, 2000. Disponível em: <http:// crop.scijournals.org/cgi/content/abstract/40/2/436>. Acesso em: 16 abr. 2009.

Croughan, T.P. Application of tissue culture techniques to the development of herbicide resistant rice. Louisiana Agriculture, v.37, p.25-26, 1994.

DAL MAGRO, T. Efeito de deriva simulada e época de aplicação do herbicida imazethapyr + imazapic no arroz irrigado (Oryza sativa L.). 2006. 65f. Dissertação (Mestrado em Fitossanidade) - Universidade Federal de Pelotas, Pelotas.

DORNELLES, S. et al. Época de entrada de água: Influência na eficiência e seletividade do herbicida ONLY ${ }^{\circledR}$. In: CONGRESSO BRASILEIRO DE ARROZ IRRIGADO, 4.; REUNIÃO DA CULTURA DO ARROZ IRRIGADO, 26., 2005, Santa Maria, RS. Anais... Santa Maria: SOSBAI, 2005. V.1, p.235-237.

ELEFTHEROHORINOS, I.L.; DHIMA, K. V. Red rice (Oryza sativa) control in rice (O. sativa) with preemergence and postemergence herbicides. Weed Technology, v.16, n.3, p.537-540, 2002. Disponível em: < http://www.bioone.org/doi/full/10.1614/0890 037X\%282002\%29016\%5B0537\%3ARROSCI\%5D2.0.CO\%3B2>. Acesso em: 16 abr. 2009. Doi: 10.1614/0890037X(2002)016[0537:RROSCI]2.0.CO;2.

EMPRESA BRASILEIRADE PESQUISA AGROPECUÁRIA EMBRAPA. Centro Nacional de Pesquisa de Solos (Rio de Janeiro, RJ). Sistema Brasileiro de Classificação dos Solos. Brasília: 1999. 412 p.

FIRMINO, L.E. et al. Movimento do herbicida imazapyr no perfil dos solos tropicais. Planta Daninha, v.26, n.1, p.223230, 2008. Disponível em: <http://www.scielo.br/ s ci elo.php ? script = sci_art text \& pid = S $0100-$ $83582008000100023 \& \operatorname{lng}=\mathrm{pt} \& \mathrm{nrm}=\mathrm{iso} \& \operatorname{tng}=\mathrm{pt}>$. Acesso em: 16 abr. 2009. Doi: 10.1590/S0100-83582008000100023 .

FLECK, N.G. et al. Controle químico seletivo de angiquinho e arroz-vermelho em arroz irrigado utilizando o sistema Clearfield $^{\circledR}$. In: CONGRESSO BRASILEIRO DE ARROZ IRRIGADO, 3.; REUNIÃO DA CULTURA DO ARROZ IRRIGADO, 25., 2003, Balneário Camboriú - SC. Anais... Itajaí: EPAGRI, 2003. p.465-467. 
FONTANA, L.C. et al. Controle de arroz-vermelho (Oryza sp.) com o herbicida nicosulfuron ou a mistura formulada de imazethapyr + imazapic. Planta Daninha, v.25, n.4, p.783790, 2007. Disponível em: <http://www.scielo.br/ s cielo.php? script = sci_art text \& pid = S $0100-$ $83582007000400015 \& \operatorname{lng}=\mathrm{pt} \& \mathrm{nrm}=\mathrm{iso} \& \mathrm{t} \operatorname{lng}=\mathrm{pt}>$. Acesso em: 16 abr. 2009. Doi: 10.1590/S0100-83582007000400015 .

GHOBRIAL, G.L. Response of irrigated dry seeded rice to nitrogen level, interior spacing, and seeding rate in a semiarid environment. International Rice Research Newsleter, v.8, n.4, p.27-28, 1983.

KRAEMER, A.F. Residual da mistura formulada dos herbicidas imazethapyr e imazapic em areas de arroz sob diferentes tipos de solo. 2008. 63f. Dissertação (Mestrado em Agronomia) - Universidade Federal de Santa Maria, Santa Maria.

LARROSA, R.F. et al. Eficiência da aplicação de nitrogênio no perfilhamento do arroz em três manejos de irrigação. Ciência Rural, v.31, n.5, p.745-749, 2001. Disponível em: <http:// www.scielo.br/scielo.php?script $=$ sci_arttext \&pid=S0103$84782001000500001 \& \operatorname{lng}=p t \& n r m=i s o \& t \operatorname{lng}=p t>$. Acesso em: 16 abr. 2009. Doi: 10.1590/S0103-84782001000500001 .

LARROSA, R.F.M. Doses e épocas de aplicação de nitrogênio na suscetibilidade do arroz temperatura baixa na fase reprodutiva. 2008. 77f. Tese (Doutorado em Agronomia) - Universidade Federal de Santa Maria, Santa Maria.

MARIOT, C.H.P. et al. Resposta de duas cultivares de arroz irrigado à densidade de semeadura e adubação nitrogenada. Pesquisa Agropecuária Brasileira, Brasília, v.38, n.2, p.233241, 2003. Disponível em: <http://www.scielo.br/ scielo.ph p ? s c ript =s ci_art text \& pid = S 0100 $204 X 2003000200010 \& \operatorname{lng}=p t \& n r m=i s o \& t \operatorname{lng}=p t>$. Acesso em: 16 abr. 2009. Doi: 10.1590/S0100-204X2003000200010.

OTTIS, B.V. et al. Imazethapyr application methods and sequences for imidazolinone-tolerant rice (Oryza sativa). Weed Technology, v.17, n.3, p.526-533, 2003. Disponível em: $<$ http://www.bioone.org/doi/full/10.1614/WT02-104>. Acesso em: 16 abr. 2009. Doi: 10.1614/WT02-104.

PANOZZO, L.E. Ocorrência de Cyperaceae e manejo de plantas daninhas em lavoura de arroz irrigado. 2008. 87f. Dissertação (Mestrado em Fitossanidade) - Universidade Federal de Pelotas, Pelotas.

PELLERIN, K.J.; WEBSTER, E.P. Imazethapyr at different rates and timings in drill- and water-seeded imidazolinonetolerant rice. Weed Technology, v.18, n.2, p.223-227, 2004. Disponível em: <http://www.bioone.org/doi/full/10.1614/WT03-005>. Acesso em: 16 abr. 2009. Doi: 10.1614/WT-03-005.
SCARPONI, L. et al. Consequences on nitrogen metabolism in soybean (Glycine max L.) as a result of imazethapyr action on acetohydroxy acid synthase. Journal of Agriculture and Food Chemistry, v.43, n.3, p.809-814, 1995. Disponível em: <http://pubs.acs.org/doi/pdf/10.1021/jf00051a047>. Acesso em: 16 abr. 2009. Doi: 10.1021/jf00051a047.

SINGH, S.P.; PILLAI, K.G. Response of scented rice varieties to nitrogen. Oryza, Cuttack, v.33, n.3, p.193-195, 1996.

STEELE, G.L. et al. Control of red rice (Oryza sativa) in imidazolinone-tolerant rice (O. sativa). Weed Technology, v.16, n.3, p.627-630, 2002. Disponível em: <http:// w w w. bi o on e.org / d o i / f u l l / 10.1614 / 0890 037X\%282002\%29016\%5B0627\%3ACORROS\%5D2.0.CO\%3B2>. Acesso em: 16 abr. 2009. Doi: 10.1614/0890037X(2002)016[0627:CORROS]2.0.CO;2.

VILLA, S.C.C. et al. Arroz tolerante a imidazolinonas: controle do arroz-vermelho, fluxo gênico e efeito residual do herbicida em culturas sucessoras não-tolerantes. Planta Daninha, v.24, n.4, p.761-768, 2006a. Disponível em: <http://www.scielo.br/ scielo.php ? s c ript = s ci_art text \& pid = S $0100-$ $83582006000400017 \& \operatorname{lng}=p t \& n r m=i s o \& t \operatorname{lng}=p t>$. Acesso em: 16 abr. 2009. Doi: 10.1590/S0100-83582006000400017 .

VILLA, S.C.C. et al. Controle de arroz-vermelho em dois genótipos de arroz (Oryza sativa) tolerantes a herbicidas do grupo das imidazolinonas. Planta Daninha, v.24, n.3, p.549555, 2006b. Disponível em: <http://www.scielo.br/ s cielo.php? script =sci_art text \& pid=S $0100-$ $83582006000300018 \& \operatorname{lng}=p t \& n r m=i s o \& t \operatorname{lng}=p t>$. Acesso em: 16 abr. 2009. Doi: 10.1590/S0100-83582006000300018 .

WIELEWICHI, A.P. et al. Absorção de nutrientes pelo arroz em resposta à calagem e à época de inicio de irrigação. Ciência Rural, v.28, n.1, p17-22, 1998. Disponível em: <http:// www.scielo.br/scielo.php?script=sci_arttext\&pid=S0103$84781998000100003 \& \operatorname{lng}=\mathrm{pt} \& n r m=\mathrm{iso} \& \operatorname{lng}=\mathrm{pt}>$. Acesso em: 16 abr. 2009. Doi: 10.1590/S0103-84781998000100003 .

YOKOYAMA, S. et al. Obtenção de cultivares de arroz irrigado resistentes a herbicidas do grupo das imidazolinonas (arroz clearfield). In: CONGRESSO BRASILEIRO DE ARROZ IRRIGADO, 3.; REUNIÃO DA CULTURA DO ARROZ IRRIGADO, 25., 2003, Balneário Camboriú, SC. Anais... Itajaí: EPAGRI, 2003. p.117-119.

ZABALZA, A. et al. Nitrogen assimilation studies using ${ }^{15} \mathrm{~N}$ in soybean plants treated with imazethapyr, and inhibitor of branched-chain amino acid biosynthesis. Journal of Agriculture and Food Chemistry, v.54, n.23, p.8818-8823, 2006. Disponível em: <http://pubs.acs.org/doi/abs/10.1021/ jf0618224>. Acesso em: 16 abr. 2009. Doi: 10.1021/jf0618224 . 